August 29, 2007

\title{
Charge Model 4 and Intramolecular Charge Polarization
}

\author{
Ryan M. Olson, Aleksandr V. Marenich, Christopher J. Cramer, ${ }^{\star}$ and Donald G. \\ Truhlar* \\ Department of Chemistry and Supercomputing Institute, University of Minnesota, 207 \\ Pleasant Street S.E., Minneapolis, MN 55455-0431
}

\begin{abstract}
Partial atomic charges provide the most widely used model for molecular charge polarization, and Charge Model 4 (CM4) is designed to provide partial atomic charges that correspond to an accurate charge distribution, even though they may be calculated with polarized double zeta basis sets with any density functional. Here we extend CM4 to six additional basis sets, and we present a model (CM4M) that is individually optimized for the M06 suite of density functionals for ten basis sets. These charge models yield class IV partial atomic charges by mapping from those obtained with Löwdin or redistributed Löwdin population analyses of density functional electronic charge distributions. CM4M/M06-2X/6-31G(d)//M06-2X/6-31+G(d,p) partial atomic charges are calculated for ethylene, $\mathrm{CH}_{n} \mathrm{Cl}_{4-n}(n=0-4)$, benzene, nitrobenzene, phenol, and fluoromethanol and used to discuss gas-phase polarization effects.
\end{abstract}




\section{Introduction}

Molecular polarization is an important aspect of molecular structure, stability and reactivity; it accounts for the nonuniform distribution of electrons within a molecule and for changes in this distribution due to various interactions. Qualitative theories of molecular polarization are often used to interpret structure and reactivity. The present article concerns polarization effects within single gas-phase molecules, which may be considered to be the starting point for all discussions of polarization.

The degree to which molecular polarization is present in a molecule is called polarity. One measure of polarity is the dipole moment; however, dipole moments are only a single measure of a molecule's polarity, and dipole moments alone are insufficient to describe the charge distributions within a molecule. Partial atomic charges provide a description of polarity that is intermediate between giving the full electronic charge distribution and giving only the dipole moment. Partial atomic charges are not physical observables because they lack a unique definition that is associated with a quantum mechanical operator, such as the dipole moment operator or the electrostatic potential operator.

The variations in the partial atomic charges with respect to changes in the chemical environment, such as substitution, complexation, or solvation, are key polarization effects that can be quantified with partial charge models. Partial atomic charges are also used in molecular mechanics force fields ${ }^{1-3}$ and for calculating the electrostatic contribution to the free energy of solvation using the generalized Born approximation. ${ }^{4-7}$

Numerous methods have been proposed for assigning partial atomic charges. These methods may be assigned to four distinct classes. ${ }^{8}$ Class I charges are based on concepts 
from classical physics and are not based on quantum mechanical calculations. Class II charges are based on a reasonable partitioning of the electron density from a quantum mechanical wave function into atomic populations. Examples of Class II charges are the charges obtained by Mulliken population analysis, ${ }^{9}$ Löwdin population analysis, 10 natural population analysis (NPA), ${ }^{11}$ Hirshfeld population analysis, ${ }^{12}$ atomic polar tensor population analysis, ${ }^{13}$ and the population analysis proposed by Bader and coworkers. ${ }^{14}$ Class III charges are partial atomic charges constrained to reproduce calculated physical observables such as electrostatic potentials and dipole moments. Schemes such as ChElP15/ChElPG ${ }^{16}$, electrostatic interaction energy (ESIE) fitting, ${ }^{17}$ and those proposed by Kollman and coworkers18,19 are examples of Class III charges. Second-generation electrostatic fitting algorithms such as RESP20 include restraints to tame unphysical conformational dependences that sometimes occur ${ }^{21,22}$ in electrostatic fitting. Finally, Class IV charges ${ }^{8}$ are defined as charges that accurately reproduce or predict either charge-dependent experimental observables or well defined observables obtained by well converged quantum mechanical calculations.

A series of Class IV charge models,8,23-26 has been developed for molecular orbital theory and density functional theory (DFT), including $a b$ initio Hartree-Fock (HF) theory and hybrid DFT as special cases. These development efforts led to the recently proposed Charge Model 4 (CM4). ${ }^{7}$ Class IV charge models have been designed to map Class II charges obtained from population analysis to accurately reproduce experimental (i.e., accurate) dipole moments. Dipole moments govern the electrostatic potential at long range. By parametrizing the models to reproduce the dipole moments of small, monofunctional molecules, we hope to obtain the correct bond polarity in both small and 
large molecules and thus to obtain realistic representations of the higher-order multipole moments as well as dipole moments in multifunctional molecules. The parameterized charge models simultaneously correct for the incompleteness of the one-electron basis set and the imperfect treatment of the electron correlation, and therefore the resulting partial atomic charges do not depend strongly on the density functional and one-electron basis set used to obtain the population analysis charges that serve as input to the mappings. Using a simple functional form for the mapping, the CM4 model provides an accurate, efficient, and stable means of assigning partial atomic charges.

The CM1 charge model ${ }^{8}$ was developed only for neglect-of-diatomic-differentialoverlap theory, but CM2, ${ }^{23-25} \mathrm{CM} 3,{ }^{26}$ and $\mathrm{CM} 47$ may be used with $a b$ initio HF theory and DFT. In this article, we extended the CM4 model so that it can be used with any basis set from for which we previously parameterized a CMx model ( $x=2$, 3, or 4). These basis sets include: 6-31G(d), ${ }^{27-31}$ 6-31+G(d), ${ }^{32}$ 6-31+G(d,p), ${ }^{33}$ MIDI!, ${ }^{34-36}$ MIDI!6D, ${ }^{34-36}$ DZVP, ${ }^{37}$ and cc-pVDZ. ${ }^{38}$ The general CM4 model was also extended to include the following additional basis sets: 6-31G(d,p), ${ }^{30,31,39} 6-31 B(d),{ }^{40}$ and 6-31B(d,p). ${ }^{40}$ The parameters of the CM4 model for a given basis set are defined to be functions only of the percentage of Hartree-Fock exchange associated with the density functional, and thus they may be used with any exchange-correlation functional. However, somewhat higher accuracy can be obtained by parametrizing for a specific density functional. With this in mind, in this article we specifically optimize a set of parameters for use with the M06 suite $^{41-43}$ of functionals (M06, M06-2X, M06-L, and M06-HF); this model will be referred to as the CM4M model. The M06-2X and CM4M methods are then used to discuss polarization effects in a representative set of small molecules. 


\section{CM4 Model}

\subsection{Theory}

CM4M is a special case of CM4, so we need only explain the equations for CM4. As in previous CMx models, 7,8,23-26 the charges for the CM4 model are mapped from Class II charges obtained using population analysis by the following formula:

$$
q_{k}=q_{k}^{0}+\sum_{k \neq k^{\prime}} T_{k k^{\prime}}\left(B_{k k^{\prime}}\right)
$$

where $q_{k}$ is the resulting CM4 charge on atom $k, q_{k}^{0}$ is the input Class II partial atomic charge, and $T_{k k^{\prime}}$ is a quadratic function of the Mayer bond order $44-46\left(B_{k k^{\prime}}\right)$ :

$$
T_{k k^{\prime}}\left(B_{k k^{\prime}}\right)=\left(D_{Z_{k} Z_{k^{\prime}}}+C_{Z_{k} Z_{k^{\prime}}} B_{k k^{\prime}}\right) B_{k k^{\prime}}
$$

The CM4 parameters are the values of $C_{Z_{k} Z_{k^{\prime}}}$ and $D_{Z_{k} Z_{k^{\prime}}}$; these parameters depend on the choice of the Class II charges used to generate the initial $q_{k}^{0}$ charges, the density functional, and the one-electron basis set. The CM4 parameters are optimized such that the errors in charge-dependent observables calculated from them are minimized. The method for determining the CM4 parameters is discussed in Section 2.4.

Löwdin population analysis (LPA) was chosen as the Class II charge model to generate initial charges for one-electron basis sets without diffuse functions, while redistributed Löwdin population analysis ${ }^{47}$ (RLPA) was chosen for use with basis sets containing diffuse functions. In a recent study, ${ }^{47}$ the dipole moments predicted by Löwdin charges were found to be more accurate than those predicted by Mulliken analysis. Furthermore, redistributed Löwdin population analysis (RLPA) was shown to lead to lower errors in dipole moments and more stable charges than either Löwdin or Mulliken 
population analysis when the one-electron basis set contains diffuse functions. In the absence of diffuse functions, RLPA charges are equivalent to LPA charges. We note that LPA charges have been shown 48,49 to depend on the orientation of the molecule with respect to a fixed coordinate system when Cartesian basis functions with angular quantum numbers greater than 1 are employed. Table 1 shows the average and standard deviation of CM4M and LPA charges for phenol over ten random rotations using the 6-31G(d) basis set. The LPA (and derived CM4M) charges vary by chemically insignificant amount so that we conclude that LPA and RLPA Class II charges are a reliable and stable set of input charges for the CM4 mapping.

\subsection{Density Functionals}

In previous work, the CM2 parameters were defined as functions of both the method used for the treatment of electron correlation and the one-electron basis set. The parameters of the more recent CM3 and CM4 models depend only on the percentage $(X)$ of Hartree-Fock exchange used by the functional and on the one-electron basis set. CM4 parameters are determined by fitting $C_{Z Z^{\prime}}$ and $D_{Z Z^{\prime}}$ as a quadratic function of $X$, for example,

$$
P_{Z Z^{\prime}}^{[X]}=b_{Z Z^{\prime}}+\sum_{i=1}^{1 \text { or } 2} X^{i} m_{Z Z^{\prime}}^{[i]}
$$

where $P$ is either $C$ or $D$ for values of $C_{Z Z^{\prime}}$ and $D_{Z Z^{\prime}}$ optimized at $X=0,25,42.8,60.6$ and 99.9 using the mPW1PWX functional ${ }^{50,51}$ as described in Ref 23 . The middle values of $X$ used for the mPW1PWX functionals correspond to named functionals, mPW1PW9150 ( $X=25), \operatorname{MPW}_{1} \mathrm{~K}^{52}(X=42.8)$, and MPW1KK 16 ( $(X=60.6)$, while the limits of $X=0$ and 
$X=99.9$ ensure a smooth fit over the entire range of $X$. In this work we extend the CM4 model to the following basis sets: MIDI!, 6-31G(d,p), 6-31B(d), 6-31B(d,p), DZVP and cc-pVDZ.

The CM4 parameters are intended to be compatible with both current and future density functionals; however, the errors in charge-dependent observables can be further reduced if one optimizes the CM4 parameters for specific functionals. As an example, the optimal set of CM4 parameters for new M06 suite of functionals ${ }^{41-43}$ were determined. This model will be referred to as CM4M.

\subsection{Basis Sets}

CM4 and CM4M parameters were obtained for all basis sets used in previous CMx models, as itemized in the introduction. Both the MIDI! and cc-pVDZ basis sets are defined to use spherical-harmonic $d$-functions, i.e., five $d$-functions are used instead of six Cartesian $d$ functions. The remaining basis sets are all defined to use Cartesian $d$ functions. The valence/core and polarization functions defined by Binning et al. ${ }^{31}$ were used to define 6-31G basis functions for bromine, and the diffuse $s$ and $p$ functions (exponent $=$ 0.035 ) for bromine were those defined by Winget and coworkers. ${ }^{26}$ The 6-31B basis sets are not defined for $\mathrm{Br}$, so we used the 6-31G definition for bromine in 6-31B calculations.

\subsection{Parameterization}

The method for determining the CM4 parameters has been described previously. ${ }^{7}$ The CM4 parameterization scheme is identical to the method used 26 in the development of CM3 parameters with one exception, namely that the CM4 $D_{H C}$ parameters describing the polarity of the $\mathrm{C}-\mathrm{H}$ bond were fit to the partial charges from the OPLS force field model ${ }^{53}$ for a series of 19 hydrocarbons, whereas the CM3 $D_{H C}$ parameters were fit to adjust the 
partial charges on ethylene and benzene to pre-selected values. The resulting CM4 partial atomic charges predict less polar $\mathrm{C}-\mathrm{H}$ bonds than the previous CM3 model, as will be discussed in Section 3.2.1.

The list of parameters optimized for the CM4 model is given in Table 2. The first step in fitting the parameters is to obtain the Mayer bond order matrix and the set of LPA and/or RLPA partial atomic charges for each of the 416 molecular geometries in the training set. The training set ${ }^{26}$ consists of 19 hydrocarbon molecules and 397 conformational isomers of 386 unique molecules.

Table 2 also describes the order in which the parameters were optimized and the number of atom-atom interactions affected significantly by each parameter during the optimization step. For this purpose, a significant interaction is defined as a bond order greater than 0.20 . The choice of 0.20 was chosen as the bond order cutoff value to report the number of significant interactions, but since CM4 charges are continuous functions of bond order even for bond orders lower than this, the use of this cutoff value for Table 2 has no effect on the calculations. The Mayer bond order is a function of the one-electron basis set and the level of theory employed; thus the values in Table 2 are exact for M062X/6-31G(d), whereas for all other methods and basis sets, the values in this table are only approximate.

As previously mentioned, the first parameter to be optimized was the $D_{H C}$

parameter. This was accomplished by minimizing the error function $(\chi)$ of the $D_{H C}$ parameter

$$
\chi^{\left[D_{H C}\right]}=\sum_{k}^{\text {atoms }}\left(q_{k}^{\mathrm{CM} 4}-q_{k}^{\mathrm{OPLS}}\right)^{2}
$$


over the set of all the atoms in the 19 molecules of the $\mathrm{C}-\mathrm{H}$ training set.

The remaining parameters were divided into five disjoint groups, labeled 2-6 in Table 2. The parameters for each group were optimized in a stepwise manner such that the parameters for previously optimized groups were held fixed. For each group the parameters were optimized to minimize the sum of the squares of the deviations of dipole moments calculated from CM4 charges from a set of target dipole moments, which were either experimental dipole moments or dipole moments calculated from one-electron expectation values of the full electron density of singe-point mPW1PW91/MG3S54 calculations. A nonlinear optimization procedure was used for the minimization.

The parameters for CM4 and CM4M for the 6-31G(d) basis set are given in Tables 3 and 4, respectively. The 6-31G(d) parameters in Table 4 differ from those previously reported ${ }^{7}$ for lithium, silicon and phosphorus. The Li-F parameter for the 6-31B basis sets were fixed at a value of 1.4. The corresponding mean unsigned errors broken down by functional group are given in Tables 5 and 6. A summary of the errors for CM4 and CM4M charges obtained from the M06-2X density functional and the 6-31G(d) basis set are given in Table 7, where they are compared to errors in dipole moments calculated from LPA charges or from the electron density itself. The CM4 and CM4M parameters and errors (as well as root-mean-square errors) for the remaining basis sets can be found in Supporting Information.

\subsection{Computational Methods}

All calculations were run with the M06-2X density functional using a locally modified version of the Gaussian 03 (G03) electronic structure program. ${ }^{55}$ All CMx charges were calculated using the MN-GSM 56 module. Molecular geometries were 
optimized using the $6-31+G(d, p)$ basis set. Partial atomic charges using Löwdin population analysis and the CM2, CM3, CM4, and CM4M models were calculated at the optimized geometries using the 6-31G(d) basis set. The CM2 model is not parameterized for M062X; therefore all reported CM2 charges were calculated using BPW9157/6-31G(d). To avoid confusion, dipole moments calculated from the quantum mechanical operator are referred to as density dipole moments. Second-order Møller-Plesset perturbation theory58 (MP2) with the aug-cc-pVTZ triple-zeta basis set ${ }^{59}$ was used to calculate density dipole moments.

\section{Polarization Effects}

\subsection{C-H Bond Polarity}

As noted in Sect. 2.4, the major difference between the CM3 and CM4 models is the treatment of the $\mathrm{C}-\mathrm{H}$ bond polarity. Since the parameter describing the $\mathrm{C}-\mathrm{H}$ bond $\left(D_{H C}\right)$ was the first parameter that was optimized, and all other parameters are optimized given a fixed value of $D_{H C}$, the value of the parameter $D_{H C}$ plays a critical role in how the model assigns partial atomic charges. Our general experience with the CM3 charge model had convinced us that the $\mathrm{C}-\mathrm{H}$ bonds were somewhat too polar; therefore we changed the strategy for obtaining $D_{H C}$ in the CM4 model, as compared to CM3. The choice we made, optimizing gas-phase charges to the OPLS charges, is formally inconsistent because OPLS charges are designed for use in liquid-phase simulations and should be slightly more polar than gas-phase charges. However, this strategy produced partial charges less polar than those we used in CM2 and CM3, and it provided accurate solvation free energies in the SM6 implicit polarizable continuum solvation model, and the fitting strategy seems to be a 
good compromise between the considerations that led to the more polar $\mathrm{C}-\mathrm{H}$ bonds of CM2 and CM3 and the practical experience that dictated less polar C-H bonds than CM3. As shown in Table 8, the CM3 model predicts the most polar $\mathrm{C}-\mathrm{H}$ bond of any of the $\mathrm{CM} x$ models; however, all CMx models predict significantly less polar $\mathrm{C}-\mathrm{H}$ bonds than Löwdin population analysis.

Polarization effects from substituting chlorine atoms for hydrogen atoms in methane are given in Table 9. The table shows that $\mathrm{C}-\mathrm{H}$ is less polar in $\mathrm{CM} 4$ than in either CM2 or CM3. Furthermore, this table illustrates a basic intramolecular polarization effect in that the atoms in the $\mathrm{C}-\mathrm{H}$ bond take on increasing positive charge as more chlorines are added, because the chlorines withdraw electron density. The majority of the charge comes from the carbon atom, which goes from having a negative partial atomic charge to a positive one along the series. A small amount of increase in the proton partial charge is also observed, consistent with the known hydrogen-bond donating capability of chloroform $>$ dichloromethane $>$ chloromethane $>$ methane. The table also illustrates that the Löwdin population analysis does not yield qualitatively correct charges, especially for $\mathrm{CCl}_{4}$; however, the trends in the Löwdin series are correct, which make a systematic mapping from Löwdin charges (as employed in CM4) a sensible procedure.

The last column of Table 9 gives charges obtained by natural population analysis (NPA) ${ }^{8}$. Comparing, for example, the charges in $\mathrm{CH}_{2} \mathrm{Cl}_{2}$, we see that $\left|q_{\mathrm{H}}^{\mathrm{NPA}}\right|>\left|q_{\mathrm{Cl}}^{\mathrm{NPA}}\right|$ whereas $\left|q_{\mathrm{H}}^{\mathrm{CM} 4}\right| \approx\left|q_{\mathrm{Cl}}^{\mathrm{CM} 4}\right|$; furthermore, $\left|q_{\mathrm{C}}^{\mathrm{NPA}}\right|<\left|q_{\mathrm{Cl}}^{\mathrm{NPA}}\right|$ whereas $\left|q_{\mathrm{C}}^{\mathrm{CM} 4}\right|>\left|q_{\mathrm{Cl}}^{\mathrm{CM} 4}\right|$, where the latter relation is expected based on electronegativity. Although one must be careful to use partial charges for the purposes for which they were intended, in solvation models it is essential that partial charges yield realistic physical observables like electrostatic 
potentials need multipole moments. In this context, it is interesting to compare the dipole moments calculated from partial charges to the density dipole (1.63 D, see Table 9) obtained using MP2/aug-cc-pVTZ; CM4 charges give 1.67D while NPA charges give 2.21D.

\subsection{Aromatic molecules}

Tables 10 and 11 provide charges for nitrobenzene and phenol. The charges on the ring carbons at the ipso, ortho, and para positions are seen to vary by $0.05-0.08$ when the substituent is changed from the electron withdrawing nitro group to the electron donating hydroxy group, but the charges at the meta position are changed by less than 0.01 . The changes are such that in nitrobenzene the ortho and para $\mathrm{CH}$ groups become net positive (cf. benzene, where the $\mathrm{CH}$ groups are necessarily net uncharged; Table 8) while in phenol they become negative. Such behavior is in line with what would be expected from conventional resonance arguments in benzene rings substituted with electron-withdrawing and electron-donating groups, respectively. Note that while the hydrogens vary by $0.01-$ 0.02 upon substitution, they are $0.02-0.03$ less positive than in CM3, reflecting the more physical reduced polarity of $\mathrm{CH}$ bonds in the CM4 models.

\subsection{Fluoromethanol}

Fluoromethanol is a small molecule that was the subject of a number of early theoretical studies because of the influence of the anomeric effect on its rotational coordinate. ${ }^{60,61}$ The anomeric effect, ${ }^{62}$ also sometimes referred to as negative hyperconjugation or the Lemieux-Edwards effect, refers to the evident stabilization of conformers having gauche compared to anti dihedral angles associated with atomic 
linkages WXYZ, where W and Y are electronegative atoms with associated lone pairs, and $\mathrm{X}$ and $\mathrm{Z}$ may be any atoms but are most often $\mathrm{H}$ or Group 14 atoms. In fluoromethanol, W is $\mathrm{F}, \mathrm{X}$ is $\mathrm{C}, \mathrm{Y}$ is $\mathrm{O}$, and $\mathrm{Z}$ is $\mathrm{H}$, and the gauche conformer is indeed predicted to be substantially lower in energy than the anti conformer. 63

The effect has been invoked in the conformational analysis of many different organic and inorganic systems, ${ }^{64}$ and is usually rationalized as deriving from stabilizing delocalization of lone-pair density on atom Y into the low-energy $\sigma^{*}$ virtual orbital associated with atoms $\mathrm{W}$ and $\mathrm{X}$. The overlap between the relevant orbitals is maximized for the gauche conformation, and in the limit of full negative hyperconjugation this delocalization has sometimes been called double-bond-no-bond resonance65 (Figure 3). Given this electronic structure description, one might expect to see polarization in the gauche conformer associated with a transfer of negative charge from oxygen to fluorine. This effect has been analyzed in terms of partial atomic charges in other systems exhibiting anomeric delocalization, 66 and we here examine a variety of charge models for the particular case of fluoromethanol (Table 12).

Considering the various models, the first issue meriting discussion is the poor performance of the NPA charges for the prediction of the molecular dipole moment. The NPA procedure involves the assignment of all electrons to orbitals associated either with a single atom (lone pairs and core orbitals) or pairs of atoms (bonding and antibonding orbitals). Assigning lone pairs entirely to individual atoms may contribute to the greater magnitude of NPA charges, and hence the larger charge-derived dipole moment compared to the other models. 
Focusing now on changes in charges as a function of conformation, all of the seven charge models do predict that the fluorine partial atomic charge becomes more negative in the gauche conformer, and the absolute magnitudes of the charges are fairly consistent across all models other than NPA. All charge models except for the two ESP algorithms predict that half to two-thirds of the charge shift onto F comes from the oxygen atom, and the remainder from the $\mathrm{CH}_{2}$ group, with the partial atomic charge of the $\mathrm{H}$ on oxygen being insensitive to conformation. The ESP charges, by contrast, predict that the $\mathrm{O}$ atom becomes more negative in the gauche conformation, forcing both the $\mathrm{H}$ atom on $\mathrm{O}$ and the $\mathrm{CH}_{2}$ group to become more positive to preserve charge neutrality. This charge arrangement does not degrade the quality of the predicted molecular dipole moment, but there are an infinite number of combinations of monopoles at the nuclear positions that will give identical dipole moments. While it is not unreasonable to imagine the $\mathrm{H}$ on $\mathrm{O}$ becoming more acidic (more positive) in the gauche conformation, it seems counterintuitive that the $\mathrm{O}$ should become more negative.

\section{Concluding Remarks}

The partial charges calculated by Charge Models 4 and 4M (CM4 and CM4M) are stable and realistic and should be useful for parameterization of force fields, or for direct use in molecular mechanics calculations where partial atomic charge parameters are lacking. CM4 and CM4M charges should also be useful for representing molecular charge distributions in solvation models, particularly because their simple algorithmic dependence on Hartree-Fock or Kohn-Sham density matrix elements, through population analysis, permits their straightforward inclusion into self-consistent reaction field models. Finally, 
the CM4 and CM4M models provide a balanced and chemically intuitive framework within which to discuss intramolecular charge polarization effects.

Acknowledgment. This work was supported in part by the office of Naval Research (award no. N00014-05-1-0538) and the National Science Foundation (grant nos. CHE-0610183 and CHE-0704974).

Supporting Information Available: CM4 and CM4M parameters for additional basis sets, mean unsigned errors and root-mean-square errors for all charge models, and geometries of all optimized molecules. This information is available free of charge via the Internet at http://pubs.acs.org. 


\section{References}

1. MacKerell, A.D. J. Comp. Chem. 2004, 25, 1584.

2. Jorgensen, W.L.; Tirado-Rives, J. Proc. Natl. Acad. Sci. USA, 2005, 102, 6665.

3. Vizcarra, C.L.; Mayo, S.L.; Curr. Opinion Chem. Biol., 2005, 9, 622.

4. Tucker, S. C.; Truhlar, D. G. Chem. Phys. Lett. 1989, 157, 164.

5. Still, W. C.; Tempczyk, A.; Hawley, R. C.; Hendrickson, T. J. Am. Chem. Soc. 1990, 112, 6127.

6. $\quad$ Cramer, C. J.; Truhlar, D. G. J. Am. Chem. Soc. 1991, 113, 8305.

7. Kelly, C. P.; Cramer, C. J.; Truhlar, D. G. J. Chem. Theory Comp. 2005, 1, 1133.

8. Storer, J. W.; Giesen, D. J.; Cramer, C. J.; Truhlar, D. G. J. Comput.-Aided Mol. Des. 1995, 9, 87.

9. Mulliken, R. S. J. Chem. Phys. 1955, 23, 1833.

10. Baker, J. Theor. Chim. Acta 1985, 68, 221.

11 Reed, A. E.; Weinstock, R. B.; Weinhold, F. J. Chem. Phys. 1985, 83, 735.

12. Hirshfeld, F. Theor. Chim. Acta 1977, 44, 129.

13. Cioslowski, J. J. Am. Chem. Soc. 1989, 111, 8333.

14. Bader, R. F. W., Matta, C. F. J. Phys. Chem. A 2004, 108, 8385.

15. Chirlian, L. E.; Francl, M. M. J. Comput. Chem. 1987, 8, 894.

16. Breneman, C. M.; Wiberg, K. B. J. Comput. Chem. 1990, 11, 361.

17. Arroyo, S. T., Martin, J. A. S., Garcia, A. H. Chem. Phys. Lett. 2002, 357, 279.

18. Besler, B. H.; Merz, K. M., Jr.; Kollman, P. A. J. Comput. Chem. 1990, 11, 431.

19. Singh, U. C.; Kollman, P. A. J. Comput. Chem. 1984, 5, 129.

20. Zhang, W. Hou, T., Qiao, X., Xu, X. J. Phys. Chem. B 2003, 107, 9071; Wang, J., Wolf, R.M., Caldwell, J.W., Kollman, P.A., Case, D.A. J. Comp. Chem. 2004, 25, 1157; Laio, A., Gervasio, F. L., VandeVondele, J., Sulpizi, M., Rothlosberger, U. J. Phys. Chem. B 2004, 108, 7963.

21. Francl, M. M., Carey, C., Chirlian, L. E., Gange, D. M. J. Comp. Chem. 1996, 17, 367

22. Green, D. F., Tidor, B. J. Phys. Chem. B 2003, 107, 10261.

23. Li, J.; Zhu, T.; Cramer, C. J.; Truhlar, D. G. J. Phys. Chem. A 1998, 102, 1820.

24. Li, J.; Xing, J.; Cramer, C. J.; Truhlar, D. G. J. Chem. Phys. 1999, 111, 885.

25. Li, J.; Williams, B.; Cramer, C. J.; Truhlar, D. G. J. Chem. Phys. 1999, 110, 724.

26. Winget, P.; Thompson, J. D.; Xidos, J. D.; Cramer, C. J.; Truhlar, D. G. J. Phys. Chem. A 2002, 106, 10707.

27. Hehre, W. J.; Radom, L.; Schleyer, P. v. R.; Pople, J. A., Ab Initio Molecular Orbital Theory. Wiley: New York, 1986.

28. $\quad$ Ditchfield, R.; Hehre, W. J.; Pople, J. A. J. Chem. Phys. 1971, 54, 724.

29. Hehre, W. J.; Ditchfield, R.; Pople, J. A. J. Chem. Phys. 1972, 56, 2257.

30. Hariharan, P. C.; Pople, J. A. Theor. Chim. Acta 1973, 28, 213.

31. Binning, R. C., Jr.; Curtiss, L. A. J. Comput. Chem. 1990, 11, 1206.

32. Clark, T.; Chandrasekhar, J.; Spitznagel, G. W.; Schleyer, P. v. R. J. Comput. Chem. 1983, 4, 294.

33. Frisch, M. J.; Pople, J. A.; Binkley, J. S. J. Chem. Phys. 1984, 80, 3265.

34. Easton, R. E.; Giesen, D. J.; Welch, A.; Cramer, C. J.; Truhlar, D. G. Theor. Chim. Acta 1996, 93, 281.

35. Li, J.; Cramer, C. J.; Truhlar, D. G. Theor. Chem. Acc. 1998, 99, 192. 
36. Thompson, J. D.; Winget, P.; Truhlar, D. G. PhysChemComm 2001, 4, 4116.

37. Godbout, N.; Salahub, D. R.; Andzelm, J.; Wimmer, E. Can. J. Chem. 1992, 70, 560.

38. Dunning, T. H., Jr. J. Chem. Phys. 1989, 90, 1007.

39. Francl, M. M.; Pietro, W. J.; Hehre, W. J.; Binkley, J. S.; Gordon, M. S.; DeFrees, D. J.; Pople, J. A. J. Chem. Phys. 1982, 77, 3654.

40. Lynch, B. J.; Zhao, Y.; Truhlar, D. G. J. Phys. Chem. A 2005, 109, 1643.

41. Zhao, Y.; Truhlar, D. G. J. Chem. Phys. 2006, 125, 194101/1.

42. Zhao, Y.; Truhlar, D. G. J. Phys. Chem. A 2006, 110, 13126.

43. Zhao, Y.; Truhlar, D. G. Theor. Chem. Acc., in press.

44. Mayer, I. Int. J. Quantum Chem. 1986, 29, 73.

45. Mayer, I. Int. J. Quantum Chem. 1986, 29, 477.

46. Mayer, I. Chem. Phys. Lett. 1983, 97, 270.

47. Thompson, J. D.; Xidos, J. D.; Sonbuchner, T. M.; Cramer, C. J.; Truhlar, D. G. PhysChemComm 2002, 5, 117.

48. Mayer, I. Chem. Phys. Lett. 2004, 393, 209.

49. Bruhn, G.; Davidson, E. R.; Mayer, I.; Clark, A.E. Int. J. Quantum Chem. 2006, 106, 2065.

50. Adamo, C.; Barone, V. J. Chem. Phys. 1998, 108, 664.

51. Perdew, J. P., In Electronic Structrure of Solids '91, Ziesche, P.; Eschrig, H., Eds. Akademie Verlag: Berlin, 1991; pp 11.

52. Lynch, B. J.; Fast, P. L.; Harris, M.; Truhlar, D. G. J. Phys. Chem. A 2000, 104, 4811.

53. Jorgensen, W. L.; Maxwell, D. S.; Tirado-Rives, J. J. Am. Chem. Soc. 1996, 118, 11225.

54. Lynch, B. J.; Zhao, Y.; Truhlar, D. G. J. Phys. Chem. A 2003, 107, 1384-1388.

55. Frisch, M. J.; Trucks, G. W.; Schlegel, H. B.; Scuseria, G. E.; Robb, M. A.; Cheeseman, J. R.; Montgomery, J. A., Jr.; Vreven, T.; Kudin, K. N.; Burant, J. C.; Millam, J. M.; Iyengar, S. S.; Tomasi, J.; Barone, V.; Munnucci, B.; Cossi, M.; Scalmani, G.; Rega, N.; Petersson, G. A.; Nakatusjui, H.; Hada, M.; Ehara, M.; Toyota, K.; Fukuda, R.; Hasegawa, J.; Ishida, M.; Nakajima, T.; Honda, Y.; Kitao, O.; Nakai, H.; Klene, M.; Li, X.; Knox, J. E.; Hratchian, H. P.; Cross, J. B.; Bakken, V.; Adamo, C.; Jaramillo, J.; Gromperts, R.; Stratmann, R. E.; Yazyev, O.; Austin, A. J.; Cammi, R.; Pomelli, C.; Ochterski, J. W.; Ayala, P. Y.; Morokuma, K.; Voth, G. A.; Salvador, P.; Foresman, J. B.; Ortiz, J. V.; Cui, Q.; Baboul, A. G.; Clifford, S.; Cioslowski, J.; Stefanov, B. B.; Lui, G.; Liashenko, A.; Piskorz, P.; Komaromi, I.; Martin, R. L.; Fox, D. J.; Keith, T.; Al-Laham, A.; Peng, C. Y.; Nanyakkara, A.; Challacombe, M.; Gill, P. M. W.; Johnson, B.; Chen, W.; Wong, M. W.; Gonzalez, C.; Pople, J. A. Gaussian 03, Revision C.02; Gaussian, Inc.: Wallingford, CT, 2004.

56. Chamberlin, A. C.; Kelly, C. P.; Xidos, J. D.; Li, J.; Thompson, J. D.; Hawkins, G. D.; Winget, P. D.; Zhu, T.; Rinaldi, D.; Liotard, D. A.; Cramer, C. J.; Truhlar, D. G.; Frisch, M. J. MN-GSM, version 6.2; Univeristy of Minnesota: Minneapolis, MN, 2007.

57. Becke, A. D. Phys. Rev. A 1988, 38, 3098. Perdew, J. P. In Electronic Structrure of Solids '91; Ziesche, P.; Eschrig, H., Eds. Akademie Verlag: Berlin, 1991; pp 11

58. Møller, C.; Plesset, M. S. Phys. Rev. 1934, 46, 618.

59. Dunning, T. H., Jr. J. Chem. Phys. 1989, 90, 1007. 
60. Radom, L.; Hehre, W. J.; Pople, J. A. J. Am. Chem. Soc. 1971, 93, 289.

61. Wolfe, S.; Rauk, A.; Tel, L. M.; Czismadia, I. G. J. Chem. Soc. B 1971, 136.

62. Kirby, A. J. The Anomeric Effect and Related Stereoelectronic Effects at Oxygen; Springer-Verlag: Berlin, 1983.

63. Cramer, C. J. Essentials of Computational Chemistry: Theories and Models; 2nd ed.; John Wiley \& Sons: Chichester, 2004, p. 23.

64. Cramer, C. J. J. Mol. Struct. (Theochem) 1996, 370, 135-146.

65. Hine, J. J. Am. Chem. Soc. 1963, 85, 3239.

66. Cramer, C. J. J. Org. Chem. 1992, 57, 7034-7043. 
Table 1. Average and standard deviation (stdev) of Löwdin and CM4M charges of phenol over 10 random rotations using M06-2X/6-31G(d)//M06-2X/6-31+G(d,p). Refer to Figure 1 for atom labels.

\begin{tabular}{llrrrr}
\hline & & \multicolumn{2}{c}{ CM4M } & \multicolumn{2}{c}{ Löwdin } \\
& & average & stdev & average & stdev \\
\cline { 3 - 6 } C1 & & 0.130 & 0.001 & 0.106 & 0.001 \\
C2, & (ortho) & -0.109 & 0.001 & -0.193 & 0.001 \\
C3, C5 & (meta) & -0.066 & 0.001 & -0.150 & 0.001 \\
C4 & (para) & -0.105 & 0.001 & -0.189 & 0.001 \\
C6 & (ortho) & -0.139 & 0.002 & -0.223 & 0.001 \\
H7 & (ortho) & 0.090 & 0.001 & 0.174 & 0.001 \\
H8, H10 & (meta) & 0.081 & 0.001 & 0.165 & 0.001 \\
H9 & (para) & 0.080 & 0.001 & 0.164 & 0.000 \\
H11 & (ortho) & 0.076 & 0.001 & 0.160 & 0.001 \\
O12 & & -0.389 & 0.001 & -0.396 & 0.001 \\
H13 & & 0.336 & 0.001 & 0.366 & 0.001 \\
\hline
\end{tabular}


Table 2. Parameters Defining the CM4 and CM4M models ${ }^{a}$

\begin{tabular}{|c|c|c|c|}
\hline Parameter & $C_{Z Z^{\prime}}$ & $D_{Z Z^{\prime}}$ & Occurrences $b$ \\
\hline $\mathrm{H}-\mathrm{C}$ & & 1 & 234 \\
\hline $\mathrm{H}-\mathrm{N}$ & & 2 & 61 \\
\hline $\mathrm{H}-\mathrm{O}$ & & 2 & 31 \\
\hline $\mathrm{H}-\mathrm{Si}$ & & 4 & 22 \\
\hline $\mathrm{H}-\mathrm{P}$ & & 5 & 25 \\
\hline $\mathrm{H}-\mathrm{S}$ & & 3 & 14 \\
\hline $\mathrm{Li}-\mathrm{C}$ & & 6 & 9 \\
\hline $\mathrm{Li}-\mathrm{N}$ & & 6 & 2 \\
\hline $\mathrm{Li}-\mathrm{O}$ & & 6 & 4 \\
\hline $\mathrm{Li}-\mathrm{F}$ & & 6 & 1 \\
\hline $\mathrm{Li}-\mathrm{S}$ & & 6 & 2 \\
\hline $\mathrm{Li}-\mathrm{Cl}$ & & 6 & 2 \\
\hline $\mathrm{C}-\mathrm{N}$ & & 2 & 149 \\
\hline $\mathrm{C}-\mathrm{O}$ & 2 & 2 & 157 \\
\hline $\mathrm{C}-\mathrm{F}$ & & 3 & 111 \\
\hline $\mathrm{C}-\mathrm{Si}$ & & 4 & 10 \\
\hline C-P & & 6 & 23 \\
\hline $\mathrm{C}-\mathrm{S}$ & & 3 & 58 \\
\hline $\mathrm{C}-\mathrm{Cl}$ & & 3 & 69 \\
\hline $\mathrm{C}-\mathrm{Br}$ & & 3 & 20 \\
\hline $\mathrm{N}-\mathrm{O}$ & & 2 & 22 \\
\hline $\mathrm{N}-\mathrm{P}$ & & 6 & 1 \\
\hline $\mathrm{O}-\mathrm{Si}$ & 5 & 5 & 12 \\
\hline $\mathrm{O}-\mathrm{P}$ & 6 & 6 & 24 \\
\hline $\mathrm{O}-\mathrm{S}$ & & 3 & 13 \\
\hline $\mathrm{F}-\mathrm{Si}$ & & 5 & 17 \\
\hline $\mathrm{F}-\mathrm{P}$ & & 6 & 9 \\
\hline $\mathrm{Si}-\mathrm{Cl}$ & & 5 & 18 \\
\hline $\mathrm{P}-\mathrm{S}$ & 6 & 6 & 9 \\
\hline $\mathrm{P}-\mathrm{Cl}$ & & 6 & 9 \\
\hline
\end{tabular}

a Columns 2 and 3 denote at which stage in the optimization process each parameter was optimized.

$b$ Number of interactions in the molecules in the parameterization where the Mayer bond order between the atom pairs was greater than 0.20 . 
Table 3. CM4M Parameters Optimized for the 6-31G(d) Basis Set for the M06 Series of Density Functionals

\begin{tabular}{|c|c|c|c|c|}
\hline & M06-L & M06 & M06-2X & M06-HF \\
\hline \multicolumn{5}{|c|}{$C_{Z Z^{\prime}}$} \\
\hline $\mathrm{C}-\mathrm{O}$ & 0.054 & 0.055 & 0.058 & 0.058 \\
\hline $\mathrm{O}-\mathrm{Si}$ & -0.063 & -0.061 & -0.066 & -0.069 \\
\hline O-P & -0.094 & -0.093 & -0.093 & -0.091 \\
\hline P-S & -0.045 & -0.047 & -0.047 & -0.042 \\
\hline \multicolumn{5}{|c|}{$D_{Z Z^{\prime}}$} \\
\hline $\mathrm{H}-\mathrm{C}$ & -0.090 & -0.091 & -0.091 & -0.099 \\
\hline $\mathrm{H}-\mathrm{N}$ & 0.031 & 0.036 & 0.039 & 0.045 \\
\hline $\mathrm{H}-\mathrm{O}$ & -0.041 & -0.039 & -0.037 & -0.036 \\
\hline $\mathrm{H}-\mathrm{Si}$ & 0.019 & 0.011 & 0.011 & 0.019 \\
\hline $\mathrm{H}-\mathrm{P}$ & 0.080 & 0.070 & 0.064 & 0.053 \\
\hline $\mathrm{H}-\mathrm{S}$ & -0.007 & -0.004 & -0.002 & 0.000 \\
\hline $\mathrm{Li}-\mathrm{C}$ & 0.448 & 0.459 & 0.472 & 0.499 \\
\hline $\mathrm{Li}-\mathrm{N}$ & 0.661 & 0.667 & 0.695 & 0.726 \\
\hline $\mathrm{Li}-\mathrm{O}$ & 0.681 & 0.681 & 0.719 & 0.752 \\
\hline $\mathrm{Li}-\mathrm{F}$ & 0.605 & 0.608 & 0.615 & 0.628 \\
\hline $\mathrm{Li}-\mathrm{S}$ & 0.542 & 0.538 & 0.539 & 0.546 \\
\hline $\mathrm{Li}-\mathrm{Cl}$ & 0.594 & 0.584 & 0.587 & 0.587 \\
\hline $\mathrm{C}-\mathrm{N}$ & 0.086 & 0.086 & 0.092 & 0.094 \\
\hline $\mathrm{C}-\mathrm{O}$ & -0.019 & -0.029 & -0.030 & -0.034 \\
\hline $\mathrm{C}-\mathrm{F}$ & 0.033 & 0.022 & 0.024 & 0.014 \\
\hline $\mathrm{C}-\mathrm{Si}$ & -0.029 & -0.030 & -0.023 & -0.013 \\
\hline $\mathrm{C}-\mathrm{P}$ & 0.130 & 0.135 & 0.136 & 0.141 \\
\hline $\mathrm{C}-\mathrm{S}$ & 0.141 & 0.140 & 0.139 & 0.137 \\
\hline $\mathrm{C}-\mathrm{Cl}$ & 0.094 & 0.096 & 0.100 & 0.105 \\
\hline $\mathrm{C}-\mathrm{Br}$ & 0.073 & 0.069 & 0.059 & 0.041 \\
\hline $\mathrm{N}-\mathrm{O}$ & -0.011 & -0.020 & -0.027 & -0.052 \\
\hline $\mathrm{N}-\mathrm{P}$ & -0.005 & -0.003 & -0.008 & -0.009 \\
\hline $\mathrm{O}-\mathrm{Si}$ & 0.134 & 0.135 & 0.145 & 0.161 \\
\hline O-P & 0.244 & 0.254 & 0.255 & 0.263 \\
\hline $\mathrm{O}-\mathrm{S}$ & 0.111 & 0.123 & 0.131 & 0.155 \\
\hline F-Si & 0.075 & 0.084 & 0.077 & 0.078 \\
\hline F-P & 0.176 & 0.187 & 0.181 & 0.181 \\
\hline $\mathrm{Si}-\mathrm{Cl}$ & 0.020 & 0.021 & 0.018 & 0.011 \\
\hline $\mathrm{P}-\mathrm{S}$ & 0.030 & 0.036 & 0.034 & 0.027 \\
\hline $\mathrm{P}-\mathrm{Cl}$ & -0.088 & -0.086 & -0.083 & -0.074 \\
\hline
\end{tabular}


Table 4. CM4 Parameters at Fixed Values of Hartree-Fock Exchange $(X=0,25$, 42.8, 60.6, 99.9) and the Quadratic Coefficients $\left(m_{Z Z^{\prime}}^{[2]}, m_{Z Z^{\prime}}^{[1]}, b_{Z Z^{\prime}}\right)$ which define the CM4 Parameters for all other values of $X$

\begin{tabular}{|c|c|c|c|c|c|c|c|c|}
\hline & 0 & 25 & 42.8 & 60.6 & 99.9 & $m_{Z Z^{\prime}}^{[2]}$ & $m_{Z Z^{\prime}}^{[1]}$ & $b_{Z Z^{\prime}}$ \\
\hline & $C_{Z Z^{\prime}}$ & & & & & & & \\
\hline $\mathrm{C}-\mathrm{O}$ & 0.052 & 0.054 & 0.055 & 0.056 & 0.056 & -0.006 & 0.010 & 0.052 \\
\hline $\mathrm{O}-\mathrm{Si}$ & -0.059 & -0.062 & -0.064 & -0.065 & -0.067 & 0.006 & -0.013 & -0.059 \\
\hline O-P & -0.089 & -0.090 & -0.090 & -0.091 & -0.095 & -0.005 & 0.000 & -0.089 \\
\hline \multirow[t]{2}{*}{ P-S } & -0.041 & -0.049 & -0.055 & -0.064 & -0.085 & -0.018 & -0.027 & -0.041 \\
\hline & $D_{Z Z^{\prime}}$ & & & & & & & \\
\hline $\mathrm{H}-\mathrm{C}$ & -0.094 & -0.097 & -0.099 & -0.102 & -0.106 & 0.000 & -0.013 & -0.094 \\
\hline $\mathrm{H}-\mathrm{N}$ & 0.041 & 0.035 & 0.031 & 0.027 & 0.017 & 0.000 & -0.024 & 0.041 \\
\hline $\mathrm{H}-\mathrm{O}$ & -0.027 & -0.035 & -0.041 & -0.047 & -0.060 & 0.000 & -0.033 & -0.027 \\
\hline $\mathrm{H}-\mathrm{Si}$ & -0.003 & 0.006 & 0.013 & 0.019 & 0.031 & 0.000 & 0.034 & -0.002 \\
\hline $\mathrm{H}-\mathrm{P}$ & 0.049 & 0.057 & 0.063 & 0.068 & 0.080 & 0.000 & 0.030 & 0.050 \\
\hline $\mathrm{H}-\mathrm{S}$ & -0.011 & -0.009 & -0.007 & -0.006 & -0.003 & 0.000 & 0.007 & -0.011 \\
\hline $\mathrm{Li}-\mathrm{C}$ & 0.473 & 0.472 & 0.473 & 0.475 & 0.483 & 0.018 & -0.007 & 0.473 \\
\hline $\mathrm{Li}-\mathrm{N}$ & 0.677 & 0.689 & 0.700 & 0.713 & 0.751 & 0.036 & 0.037 & 0.677 \\
\hline $\mathrm{Li}-\mathrm{O}$ & 0.676 & 0.692 & 0.706 & 0.723 & 0.772 & 0.045 & 0.050 & 0.676 \\
\hline $\mathrm{Li}-\mathrm{F}$ & 0.595 & 0.608 & 0.620 & 0.634 & 0.675 & 0.039 & 0.041 & 0.595 \\
\hline $\mathrm{Li}-\mathrm{S}$ & 0.540 & 0.542 & 0.544 & 0.547 & 0.554 & 0.007 & 0.007 & 0.540 \\
\hline $\mathrm{Li}-\mathrm{Cl}$ & 0.576 & 0.590 & 0.601 & 0.613 & 0.640 & 0.009 & 0.056 & 0.576 \\
\hline $\mathrm{C}-\mathrm{N}$ & 0.095 & 0.090 & 0.086 & 0.082 & 0.072 & -0.004 & -0.019 & 0.095 \\
\hline $\mathrm{C}-\mathrm{O}$ & -0.004 & -0.021 & -0.032 & -0.043 & -0.065 & 0.008 & -0.069 & -0.004 \\
\hline C-F & 0.060 & 0.033 & 0.014 & -0.004 & -0.045 & 0.000 & -0.106 & 0.060 \\
\hline $\mathrm{C}-\mathrm{Si}$ & -0.043 & -0.033 & -0.026 & -0.020 & -0.006 & 0.000 & 0.037 & -0.043 \\
\hline C-P & 0.127 & 0.131 & 0.134 & 0.136 & 0.140 & -0.005 & 0.019 & 0.127 \\
\hline C-S & 0.140 & 0.138 & 0.137 & 0.136 & 0.132 & -0.002 & -0.005 & 0.140 \\
\hline $\mathrm{C}-\mathrm{Cl}$ & 0.106 & 0.101 & 0.097 & 0.093 & 0.085 & 0.000 & -0.021 & 0.106 \\
\hline $\mathrm{C}-\mathrm{Br}$ & 0.066 & 0.059 & 0.054 & 0.049 & 0.037 & 0.000 & -0.029 & 0.066 \\
\hline $\mathrm{N}-\mathrm{O}$ & 0.008 & -0.017 & -0.032 & -0.046 & -0.078 & 0.012 & -0.096 & 0.007 \\
\hline $\mathrm{N}-\mathrm{P}$ & -0.017 & -0.011 & -0.006 & -0.002 & 0.009 & 0.000 & 0.026 & -0.017 \\
\hline $\mathrm{O}-\mathrm{Si}$ & 0.105 & 0.130 & 0.148 & 0.166 & 0.203 & 0.000 & 0.098 & 0.106 \\
\hline O-P & 0.220 & 0.241 & 0.256 & 0.272 & 0.310 & 0.000 & 0.090 & 0.219 \\
\hline O-S & 0.091 & 0.119 & 0.140 & 0.160 & 0.206 & 0.000 & 0.116 & 0.090 \\
\hline F-Si & 0.028 & 0.064 & 0.090 & 0.117 & 0.177 & 0.000 & 0.149 & 0.027 \\
\hline $\mathrm{F}-\mathrm{P}$ & 0.131 & 0.167 & 0.192 & 0.217 & 0.272 & 0.000 & 0.141 & 0.131 \\
\hline $\mathrm{Si}-\mathrm{Cl}$ & 0.039 & 0.025 & 0.016 & 0.007 & -0.013 & 0.000 & -0.052 & 0.039 \\
\hline P-S & 0.035 & 0.037 & 0.041 & 0.047 & 0.063 & 0.023 & 0.006 & 0.035 \\
\hline $\mathrm{P}-\mathrm{Cl}$ & -0.066 & -0.078 & -0.085 & -0.093 & -0.109 & 0.000 & -0.043 & -0.067 \\
\hline
\end{tabular}


Table 5. Mean Unsigned Errors in Debyes for CM4M Predicted Dipole Moments Using the M06 Suite of Density Functionals and the 6-31G(d) Basis Set

\begin{tabular}{|c|c|c|c|c|c|}
\hline Compounds & no. $^{\mathrm{a}}$ & M06-L & M06 & M06-2X & M06-HF \\
\hline inorganics & 10 & 0.24 & 0.23 & 0.23 & 0.23 \\
\hline alcohols,phenol & 13 & 0.12 & 0.13 & 0.12 & 0.12 \\
\hline ethers & 11 & 0.13 & 0.12 & 0.12 & 0.13 \\
\hline aldehydes & 5 & 0.22 & 0.22 & 0.17 & 0.13 \\
\hline ketones & 11 & 0.18 & 0.17 & 0.17 & 0.17 \\
\hline carboxylic acids & 9 & 0.15 & 0.18 & 0.20 & 0.23 \\
\hline esters & 6 & 0.24 & 0.22 & 0.18 & 0.15 \\
\hline other C, H, O & 12 & 0.21 & 0.19 & 0.20 & 0.20 \\
\hline aliphatic amines & 13 & 0.17 & 0.19 & 0.20 & 0.22 \\
\hline aromatic nitrogen & 11 & 0.23 & 0.22 & 0.21 & 0.19 \\
\hline nitriles & 12 & 0.18 & 0.19 & 0.17 & 0.18 \\
\hline imines & 6 & 0.34 & 0.32 & 0.34 & 0.37 \\
\hline other CHN & 14 & 0.13 & 0.12 & 0.12 & 0.16 \\
\hline amides & 17 & 0.15 & 0.17 & 0.16 & 0.17 \\
\hline nitrohydrocarbons & 5 & 0.14 & 0.13 & 0.11 & 0.17 \\
\hline bifunctional HCNO & 11 & 0.19 & 0.21 & 0.22 & 0.22 \\
\hline HCNO polar & 162 & 0.18 & 0.18 & 0.18 & 0.19 \\
\hline F contaning & 39 & 0.15 & 0.14 & 0.13 & 0.13 \\
\hline $\mathrm{Cl}$ contaning & 33 & 0.12 & 0.11 & 0.11 & 0.10 \\
\hline Br contaning & 14 & 0.13 & 0.11 & 0.13 & 0.13 \\
\hline halogenated bifunctionals & 23 & 0.20 & 0.18 & 0.18 & 0.17 \\
\hline thiols & 8 & 0.12 & 0.11 & 0.11 & 0.10 \\
\hline sulfides, disulfides & 9 & 0.23 & 0.24 & 0.24 & 0.23 \\
\hline other sulfur & 23 & 0.41 & 0.40 & 0.40 & 0.40 \\
\hline phosphorus & 10 & 0.35 & 0.34 & 0.34 & 0.34 \\
\hline multi-functional P & 13 & 0.30 & 0.28 & 0.27 & 0.28 \\
\hline $\mathrm{S}$ and $\mathrm{P}$ containing & 7 & 0.20 & 0.20 & 0.15 & 0.12 \\
\hline $\mathrm{CH}$ and $\mathrm{Si}$ & 9 & 0.12 & 0.12 & 0.12 & 0.13 \\
\hline $\mathrm{CHO}$ and $\mathrm{Si}$ & 9 & 0.33 & 0.33 & 0.32 & 0.30 \\
\hline $\mathrm{CH}, \mathrm{Si}$ and halogen & 18 & 0.40 & 0.40 & 0.41 & 0.45 \\
\hline lithium compounds & 16 & 0.22 & 0.20 & 0.19 & 0.18 \\
\hline CM3 Training Set & 397 & 0.21 & 0.20 & 0.20 & 0.20 \\
\hline
\end{tabular}

$a$ Number of occurrences of various functional groups in the training set. 
Table 6. Mean Unsigned Errors (in debyes) for CM4 Dipole Moments Using the mPW1PWX Density Functional with Various Percentages $X$ of Hartree-Fock Exchange and the 6-31G(d) Basis Set

\begin{tabular}{|c|c|c|c|c|c|c|}
\hline Compounds & no. ${ }^{\mathrm{a}}$ & $X=0$ & $X=25$ & $X=42.8$ & $X=60.6$ & $X=99.9$ \\
\hline inorganics & 10 & 0.24 & 0.23 & 0.23 & 0.24 & 0.27 \\
\hline alcohols,phenol & 13 & 0.12 & 0.12 & 0.12 & 0.12 & 0.13 \\
\hline ethers & 11 & 0.14 & 0.13 & 0.12 & 0.12 & 0.11 \\
\hline aldehydes & 5 & 0.22 & 0.19 & 0.18 & 0.16 & 0.14 \\
\hline ketones & 11 & 0.19 & 0.17 & 0.16 & 0.15 & 0.13 \\
\hline carboxylic acids & 9 & 0.14 & 0.18 & 0.20 & 0.22 & 0.24 \\
\hline esters & 6 & 0.20 & 0.20 & 0.20 & 0.20 & 0.20 \\
\hline other CHO & 12 & 0.23 & 0.20 & 0.19 & 0.18 & 0.17 \\
\hline aliphatic amines & 13 & 0.19 & 0.19 & 0.18 & 0.18 & 0.17 \\
\hline aromatic nitrogen & 11 & 0.23 & 0.22 & 0.22 & 0.23 & 0.25 \\
\hline nitriles & 12 & 0.19 & 0.18 & 0.18 & 0.18 & 0.18 \\
\hline imines & 6 & 0.32 & 0.32 & 0.32 & 0.32 & 0.32 \\
\hline other CHN & 14 & 0.15 & 0.12 & 0.11 & 0.11 & 0.14 \\
\hline amides & 17 & 0.13 & 0.15 & 0.17 & 0.18 & 0.22 \\
\hline nitrohydrocarbons & 5 & 0.12 & 0.12 & 0.12 & 0.14 & 0.18 \\
\hline bifunctional HCNO & 11 & 0.22 & 0.20 & 0.20 & 0.20 & 0.20 \\
\hline HCNO polar & 162 & 0.18 & 0.18 & 0.17 & 0.18 & 0.18 \\
\hline F contaning & 39 & 0.16 & 0.15 & 0.14 & 0.14 & 0.14 \\
\hline $\mathrm{Cl}$ contaning & 33 & 0.12 & 0.11 & 0.11 & 0.10 & 0.10 \\
\hline Br contaning & 14 & 0.14 & 0.13 & 0.13 & 0.12 & 0.10 \\
\hline halogenated bifunctionals & 23 & 0.20 & 0.18 & 0.17 & 0.17 & 0.17 \\
\hline thiols & 8 & 0.11 & 0.11 & 0.12 & 0.13 & 0.17 \\
\hline sulfides, disulfides & 9 & 0.21 & 0.23 & 0.25 & 0.27 & 0.32 \\
\hline other sulfur & 23 & 0.38 & 0.41 & 0.43 & 0.45 & 0.51 \\
\hline phosphorus & 10 & 0.32 & 0.34 & 0.36 & 0.37 & 0.40 \\
\hline multi-functional $\mathrm{P}$ & 13 & 0.27 & 0.27 & 0.28 & 0.28 & 0.29 \\
\hline $\mathrm{S}$ and $\mathrm{P}$ containing & 7 & 0.16 & 0.15 & 0.15 & 0.14 & 0.15 \\
\hline $\mathrm{CH}$ and $\mathrm{Si}$ & 9 & 0.13 & 0.13 & 0.13 & 0.13 & 0.13 \\
\hline $\mathrm{CHO}$ and $\mathrm{Si}$ & 9 & 0.34 & 0.33 & 0.32 & 0.32 & 0.30 \\
\hline $\mathrm{CH}$, Si and halogen & 18 & 0.40 & 0.40 & 0.41 & 0.41 & 0.42 \\
\hline lithium compounds & 16 & 0.20 & 0.19 & 0.20 & 0.20 & 0.21 \\
\hline CM3 Training Set & 397 & 0.20 & 0.20 & 0.20 & 0.20 & 0.21 \\
\hline
\end{tabular}

$a$ Number of occurrences of various functional groups in the training set. 
Table 7. Mean-Signed (MSE), Mean-Unsigned (MUE) and Root-Mean Squared (RMS) Errors (in debyes) for Dipole Moments calculated using Löwdin (LPA), General CM4 and optimized CM4M Partial Charges for the M06 series of functionals using the 6-31G(d) Basis Set.

\begin{tabular}{|c|c|c|c|c|c|c|c|c|c|c|c|c|}
\hline & \multicolumn{3}{|c|}{ M06-L } & \multicolumn{3}{|c|}{ M06 } & \multicolumn{3}{|c|}{ M06-2X } & \multicolumn{3}{|c|}{ M06-HF } \\
\hline & MSE & MUE & RMS & MSE & MUE & RMS & MSE & MUE & RMS & MSE & MUE & RMS \\
\hline LPA & 0.35 & 0.62 & 1.06 & 0.32 & 0.63 & 1.08 & 0.35 & 0.65 & 1.10 & 0.30 & 0.66 & 1.12 \\
\hline CM4 & -0.08 & 0.24 & 0.32 & -0.01 & 0.21 & 0.29 & 0.12 & 0.24 & 0.32 & 0.25 & 0.36 & 0.44 \\
\hline CM4M & 0.00 & 0.21 & 0.29 & 0.01 & 0.20 & 0.28 & 0.00 & 0.20 & 0.28 & 0.01 & 0.20 & 0.28 \\
\hline Density & 0.01 & 0.20 & 0.25 & -0.03 & 0.17 & 0.22 & -0.04 & 0.19 & 0.24 & -0.14 & 0.23 & 0.30 \\
\hline
\end{tabular}


Table 8. Charge (a.u.) on hydrogens in ethylene and benzene calculated using M062X/6-31G(d)//M06-2X/6-31+G(d,p).

\begin{tabular}{lrrrrc} 
& \multicolumn{2}{c}{ CM4M } & \multicolumn{2}{l}{ CM4 } & \multicolumn{2}{c}{ CM3 } & \multicolumn{2}{l}{ CM2 } & \multicolumn{1}{c}{ Löwdin } \\
\cline { 2 - 6 } Ethylene & 0.07 & 0.06 & 0.09 & 0.08 & 0.15 \\
Benzene & 0.08 & 0.07 & 0.10 & 0.09 & 0.16 \\
\hline
\end{tabular}


Table 9. Partial atomic charges (a.u.) and molecular dipole moments (debye) calculated using CM4M, CM4, CM3,CM2, ${ }^{a}$ and NPA with M06-2X/6-31G(d)//M06-2X/6$31+G(d, p)$.

\begin{tabular}{|c|c|c|c|c|c|c|}
\hline & CM4M & CM4 & CM3 & $\mathrm{CM}^{a}{ }^{a}$ & Löwdin & NPA \\
\hline \multicolumn{7}{|l|}{$\mathrm{CH}_{4}$} \\
\hline $\mathrm{C}$ & -0.31 & -0.27 & -0.40 & -0.37 & -0.66 & -0.93 \\
\hline $\mathrm{H}$ & 0.08 & 0.07 & 0.10 & 0.09 & 0.16 & 0.23 \\
\hline \multicolumn{7}{|l|}{$\mathbf{C H}_{3} \mathbf{C l}(1.93 \mathrm{D})^{b}$} \\
\hline $\mathrm{C}$ & -0.13 & -0.11 & -0.22 & -0.185 & -0.485 & -0.67 \\
\hline $\mathrm{H}$ & 0.095 & 0.09 & 0.12 & 0.11 & 0.18 & 0.25 \\
\hline $\mathrm{Cl}$ & -0.15 & -0.15 & -0.13 & -0.15 & -0.055 & -0.075 \\
\hline Dipole Moment & 1.79 & 1.69 & 1.71 & 1.85 & 1.37 & 1.88 \\
\hline \multicolumn{7}{|c|}{$\mathbf{C H}_{\mathbf{2}} \mathbf{C l}_{\mathbf{2}}(1.63 \mathrm{D})^{b}$} \\
\hline $\mathrm{C}$ & -0.01 & -0.01 & -0.10 & -0.05 & -0.38 & -0.50 \\
\hline $\mathrm{H}$ & 0.11 & 0.10 & 0.13 & 0.13 & 0.195 & 0.27 \\
\hline $\mathrm{Cl}$ & -0.11 & -0.10 & -0.08 & -0.10 & -0.01 & -0.22 \\
\hline Dipole Moment & 1.67 & 1.55 & 1.575 & 1.75 & 1.21 & 2.21 \\
\hline \multicolumn{7}{|l|}{$\mathbf{C H C l}_{3}(1.06 \mathrm{D})^{b}$} \\
\hline $\mathrm{C}$ & 0.08 & 0.07 & -0.01 & 0.055 & -0.30 & -0.37 \\
\hline $\mathrm{H}$ & 0.13 & 0.12 & 0.15 & 0.145 & 0.205 & 0.29 \\
\hline $\mathrm{Cl}$ & -0.07 & -0.06 & -0.045 & -0.07 & 0.03 & 0.03 \\
\hline Dipole Moment & 1.19 & 1.09 & 1.12 & 1.275 & 0.82 & 1.32 \\
\hline \multicolumn{7}{|l|}{$\mathrm{CCl}_{4}$} \\
\hline $\mathrm{C}$ & 0.15 & 0.125 & 0.06 & 0.15 & -0.24 & -0.29 \\
\hline $\mathrm{Cl}$ & -0.04 & -0.03 & -0.015 & -0.04 & 0.06 & 0.07 \\
\hline
\end{tabular}

${ }^{a}$ CM2 charges are not defined for M06-2X. The CM2 charge listed was calculated using BPW91/6-31G(d)//M06-2X/6-31+G(d,p).

$b$ The value in parentheses is the density dipole moment calculated using MP2/aug-ccpVTZ. 
Table 10. CM4M, CM4, CM3 and Löwdin Partial Atomic Charges (a.u.) of Nitrobenzene Calculated Using M06-2X/6-31G(d)//M06-2X/6-31+G(d,p). Refer to Figure 2 for atom labels.

C1

C2, C6 (ortho)

C3, C5 (meta)

C4 (para)

H7, H11 (ortho)

H8, H10 (meta)

H9 (para)

N12

O13, $\mathrm{O} 14$

Dipole moment (debye)

\begin{tabular}{cccc} 
CM4M & CM4 & CM3 & Löwdin \\
\hline 0.07 & 0.065 & 0.055 & -0.00 \\
-0.06 & -0.05 & -0.08 & -0.14 \\
-0.07 & -0.06 & -0.09 & -0.15 \\
-0.05 & -0.045 & -0.08 & -0.14 \\
0.11 & 0.10 & 0.135 & 0.20 \\
0.09 & 0.08 & 0.11 & 0.18 \\
0.09 & 0.08 & 0.11 & 0.17 \\
0.17 & 0.13 & 0.14 & 0.32 \\
-0.21 & -0.19 & -0.19 & -0.25
\end{tabular}

4.39

4.155

4.22

4.58 
Table 11. CM4M, CM4, CM3 and Löwdin Partial Atomic Charges (a.u) of Phenol Calculated Using M06-2X/6-31G(d)//M06-2X/6-31+G(d,p). Refer to Figure 1 for atom labels.

\begin{tabular}{lccccc}
\hline & & CM4M & CM4 & CM3 & Löwdin \\
\cline { 3 - 6 } C1 & & 0.13 & 0.12 & 0.10 & 0.11 \\
C2, & (ortho) & -0.11 & -0.10 & -0.13 & -0.19 \\
C3, CM5 & (meta) & -0.07 & -0.06 & -0.09 & -0.15 \\
C4 & (para) & -0.10 & -0.09 & -0.125 & -0.19 \\
C6 & (ortho) & -0.14 & -0.13 & -0.16 & -0.22 \\
H7 & (ortho) & 0.09 & 0.08 & 0.11 & 0.175 \\
H8, H10 & (meta) & 0.08 & 0.07 & 0.10 & 0.17 \\
H9 & (para) & 0.08 & 0.07 & 0.10 & 0.16 \\
H11 & (ortho) & 0.075 & 0.07 & 0.10 & 0.16 \\
O12 & & -0.39 & -0.37 & -0.35 & -0.40 \\
H13 & & 0.335 & 0.33 & 0.33 & 0.36 \\
\multicolumn{2}{l}{ Dipole moment (debye) } & & & & \\
\hline
\end{tabular}


Table 12. Atomic and Group Partial Charges (a.u.) and Dipole Moments (debye) in anti and gauche Conformers of Fluoromethanol from M06-2X/6-31G(d)//M06-2X/631+G(d,p) Analyses

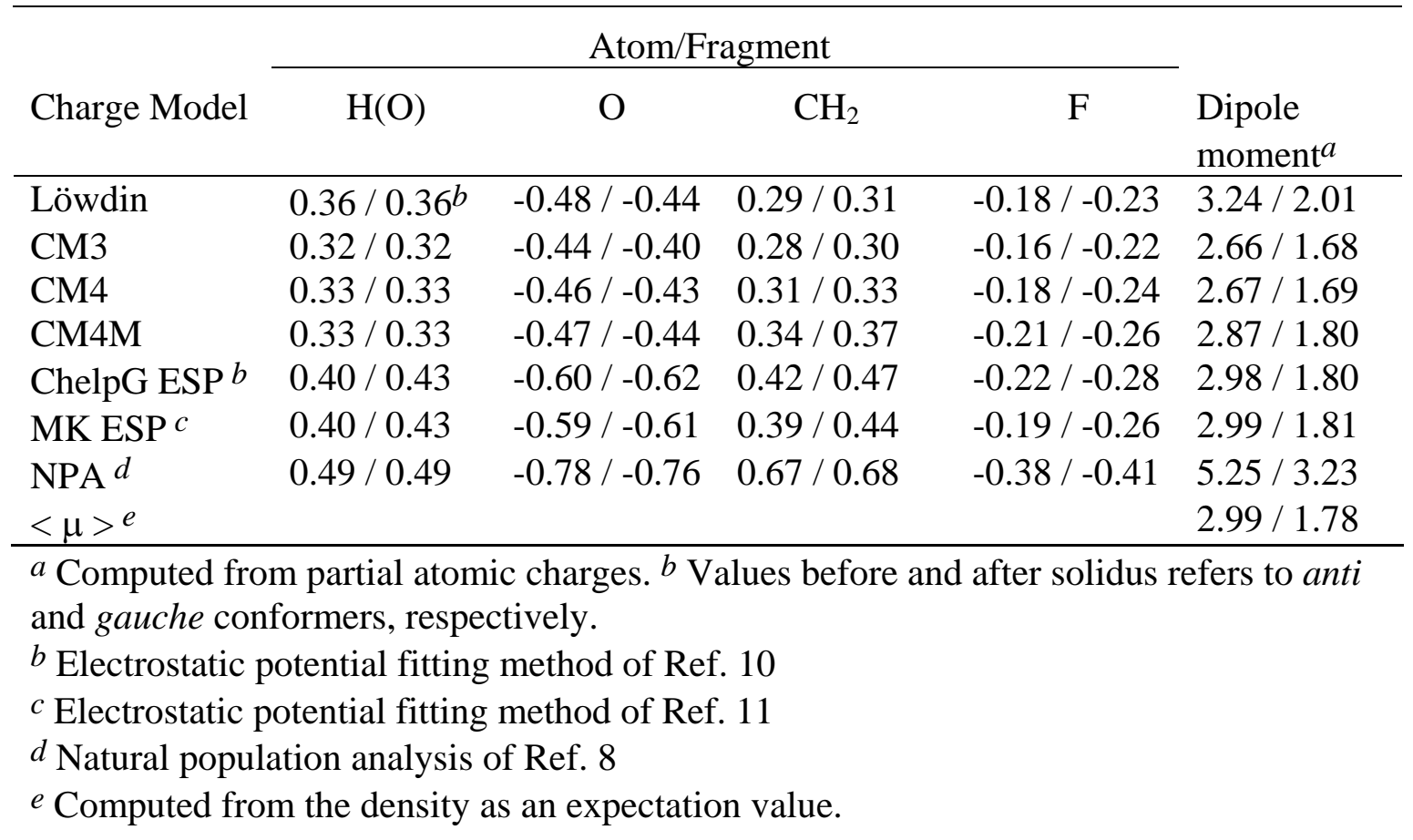




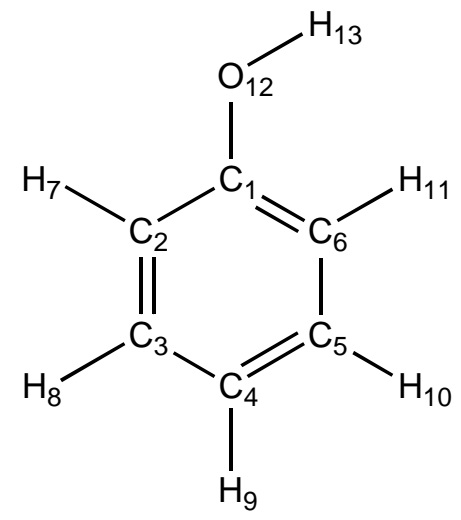

Figure 1. Atom labels in phenol. 


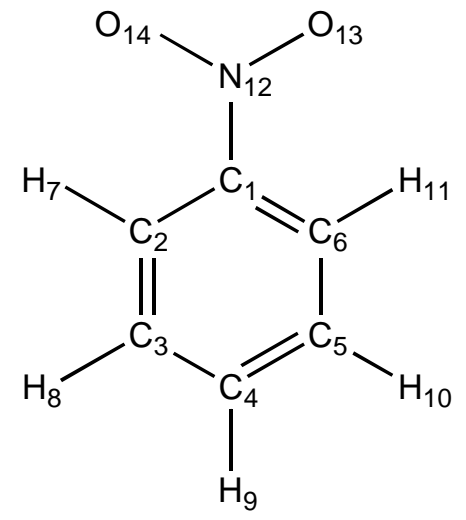

Figure 2. Atom labels in nitrobenzene. 


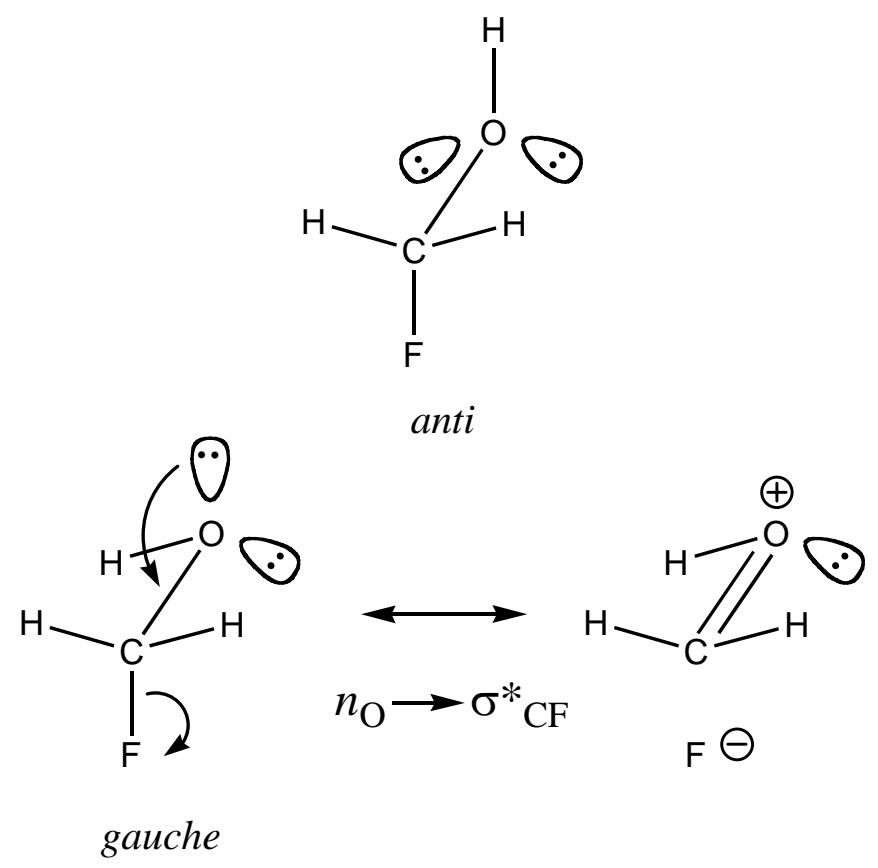

Figure 3. Anomeric delocalization in the gauche conformer of fluoromethanol compared to the anti 